\title{
ARSENIC ADSORPTION CHARACTERISTICS OF ADSORBENT PREPARED FROM SPINACIA OLERACEA (SPINACH) LEAVES
}

\author{
Prakash Kumar Jha* and Vinay Kumar Jha* \\ *Central Department of Chemistry, Tribhuvan University, Kirtipur, Kathmandu, Nepal.
}

\begin{abstract}
The dry spinach leaves fine powder was modified by activation with conc. $\mathrm{H}_{2} \mathrm{SO}_{4}$ and the adsorbent material was then characterized by using FTIR, EDX, optical microscopy, XRD analysis and methylene blue adsorption method. The EDX result showed about $95 \%$ carbon in the adsorbent material. The maximum specific surface area measured was $499 \mathrm{~m}^{2} / \mathrm{g}$. The weak and broad XRD diffraction peaks at $2 \theta$ angles 20.5 and $42^{\circ}$ were characterized as of activated carbon with the appearance of sharp peak of $\mathrm{SiO}_{2}$ at $2 \theta$ angle $26.37^{\circ}$. Optical microscopy Image analysis showed the Porous nature of adsorbents. The adsorption of arsenite on the modified spinach leaves powder adsorbent was investigated by varying different experimental parameters such as $\mathrm{pH}$, adsorbent dose, contact time and As (III) ion concentration. The adsorption process was found to be best fitted to Langmuir adsorption isotherm model controlled by pseudo-second-order kinetics with the rate constant value $0.01830 \mathrm{~g} /(\mathrm{mg} \cdot \mathrm{min})$. The maximum adsorption was observed at $\mathrm{pH} 6$ at room temperature. The maximum adsorption capacity for As (III) on modified spinach leaves powder was found to be $58.480 \mathrm{mg} / \mathrm{g}$. The value of $\Delta \mathrm{G}$ was $-22 \mathrm{~kJ} / \mathrm{mole}$ which confirmed the adsorption process was favored by physisorption. The slope of the linear plot of $\mathrm{Q}_{\mathrm{t}} \mathrm{vs} \mathrm{t}^{0.5}$ was linear but not passed through the origin, which indicates that, the intraparticle diffusion was not only rate controlling step.
\end{abstract}

Keywords: Acid activated carbon; Adsorption; Arsenic; Spinach leaves.

\section{INTRODUCTION}

Any chemical, biological or physical change in water quality that has a harmful effect on living organisms or, makes water unsuitable for desired uses, is known as water pollution. It is a major environmental problem faced by modern society that leads to ecological disequilibrium and health hazards ${ }^{1}$. Various types of pollutants responsible for water pollution are sewage and other oxygen demanding wastes, infectious agents, plant nutrients, exotic organic chemical, inorganic mineral and chemical compound, sediments, radioactive substances, thermal pollution (heat), oils, detergents etc.

Heavy metals are naturally occurring elements that have high atomic weight (63.5-200.6) and a specific density of more than 5 grams per cubic centimeter ${ }^{2}$. It enters the aquatic environment through domestic sewage, mining wastes, anthropogenic activities caused by industrial effluents, erosion of geological matrix and through atmospheric deposition ${ }^{3}$.

Arsenic exists in two forms i.e. inorganic and organic form. In inorganic form, arsenic combines with elements such as oxygen, chlorine and sulphur. In organic form arsenic combines with carbon and hydrogen. Inorganic forms of arsenic are more hazardous than its organic form. Arsenic occurs in different oxidation states $(-3,0,+3$ and $+5)^{4}$. The elemental states such as -3 and 0 are extremely rare whereas +3 and +5 oxidation states are commonly found in water systems depending on the prevailing redox conditions. The As (III) is found primarily as $\mathrm{H}_{3} \mathrm{AsO}_{3}$, $\mathrm{H}_{2} \mathrm{AsO}_{3}{ }^{-}, \mathrm{HAsO}_{3}{ }^{2-}$ and $\mathrm{AsO}_{3}{ }^{3-}$ under reducing environment

Author for Correspondence: Vinay Kumar Jha, Central Department of Chemistry, Tribhuvan University, Kirtipur.

E-mail: vinayj2@yahoo.com

Received: 10 Aug 2020; First Review: 30 Aug 2020; Second Review: 3 Sep 2020; Accepted: 5 Sep 2020.

Doi: https://doi.org/10.3126/sw.v14i14.34987 
whereas different hydrolysis species of As (V) such as $\mathrm{H}_{3} \mathrm{AsO}_{4}, \mathrm{H}_{3} \mathrm{AsO}_{4}{ }^{-}, \mathrm{HAsO}_{4}{ }^{2-}$ can be present in water with dissolved oxygen or oxidizing environment ${ }^{5}$. The As (III) is more toxic, hard to remove and is found in reducing conditions ${ }^{6}$.

The arsenic contamination occurs as the result of natural phenomenon such as volcanic eruptions, soil erosion and anthropogenic activities. Some other sources of arsenic are several industrially produced arsenic containing compounds such as insecticides, herbicides, fungicides, algaecides, sheep dips, wood preservatives and dye stuffs $\mathrm{etc}^{7}$.

In 1993, WHO had lowered the baseline of arsenic from 50 to $10 \mu \mathrm{gL}^{-1}$ for safe limit for arsenic concentrations in drinking water while in Nepal it is $50 \mu \mathrm{gL}^{-1}$ limit. The most stringent standard currently set for acceptable arsenic concentration in drinking water is implemented by Australia, which has a national standard of $7 \mu \mathrm{gL}^{-1} .89 .8 \%$ of the samples of groundwater contamination by arsenic in Nepal have shown a concentration lower than $10 \mu \mathrm{gL}^{-1}$, $7.9 \%$ in the range $10-50 \mu \mathrm{gL}^{-1}$ and $2.3 \%$ higher than 50 $\mu \mathrm{gL}^{-1}$.

The district Ilam, Jhapa, Morang, Udaypur, Mahottary, Parsa, Kathmandu, Lalitpur, Chitwan, Palpa, Dang and Bardiya had reported the low level of arsenic contamination. The district such as Sunsari, Saptari, Siraha, Dhanusha, Sarlahi, Rauthat, Bara, Nawalparasi, Rupandehi, Kapilbastu, Banke, Kailali and Kanchanpur showed the arsenic contamination varying from the degree of $10-50 \mu \mathrm{gL}^{-1}$ and even higher than $50 \mu \mathrm{g} / \mathrm{L}^{8}$.

Exposure of arsenic occurs from inhalation, absorption through the skin and primarily by ingestion of, for example, contaminated drinking water. Arsenic occurs as relatively nontoxic organic compounds in food. Clinical features of high level of Arsenic exposure include both acute and chronic arsenic toxicity ${ }^{9}$ Several epidemiological studies have reported a strong association between arsenic exposure and increased risk of both carcinogenic and systemic health effects. Recent report of large population, that have been exposed to high concentrations of arsenic in their drinking water displayed various clinic-pathological conditions including cardiovascular and peripheral vascular disease, developmental anomalies, neurologic and neurobehavioral disorders, diabetes, hearing loss, portal fibrosis, hematologic disorders (anemia, leukopenia and eosinophilia) and carcinoma. All organ systems including the cardiovascular, dermatologic, nervous, hepatobiliary, renal, gastro-intestinal and respiratory systems are virtually affected by arsenic exposure. In many arsenic contaminated areas, researchers pointed significantly higher standardized mortality rates for persons suffering from cancers of the bladder, kidney, skin and liver. The severity of adverse health effect is related to the chemical form of arsenic and also time and dose dependent ${ }^{7}$.

Several methods used to mitigate arsenic contamination are co-precipitation, liquid-liquid extraction, ion exchange, ultrafiltration, adsorption etc. A conventional method by co-precipitation-coagulation with lime and ferric salts followed by adsorption on to the resulting ferric hydroxide flocs was faced with difficulties in safe separation and handling of the contaminated sludge. Anion exchangers showed low sensitivity in presence of competing anions. Resins used for this purpose are expensive ${ }^{10}$.

\section{Spinach and its uses}

Indian spinach is also called as Spinacia Oleracea. It is a leafy vegetable. Its production has reached 20.79 million tons in 2011. The dominant producer of spinach is China (i.e. 18.78 million tons). Spinach is eaten by people mainly for its characteristics green color, nutritional contents such as carotenes, vitamin $\mathrm{C}$ and minerals such as calcium and $\operatorname{iron}^{11}$.

Improvisation of adsorption using low cost adsorbent materials such as readily available agricultural waste and their physic-chemical modification in order to introduce surface functional groups is one of the most significant ways to enhance adsorption efficiency of the adsorbent. Therefore, in this study, acid activated carbon prepared from spinach leaves powder is used for the remediation of arsenic from aqueous solution. 


\section{MATERIALS AND METHODS}

\section{Materials}

Waste spinach leaves obtained from local vegetable markets of Janakpur, Nepal. All the chemicals needed for the purpose were obtained from different manufacturers mentioned at particular places and the reagents were AR/LR grades and were used without further purification.

\section{Preparation of adsorbent from spinach leaves}

The spinach leaves sample was washed dried and then ground using mortar to make fine powder like. The powdered sample was stored in a labeled container and it was abbreviated as DSL (dry spinach leaves powder). $30 \mathrm{~g}$ of dried DSL was mixed together with $60 \mathrm{~mL}$ of concentrated sulfuric acid $(96 \%)$ in an $800 \mathrm{~mL}$ round bottom flask. The mixture was refluxed at $100{ }^{\circ} \mathrm{C}$ in an oil bath by 3 pathways. It was refluxed continuously for 6 hours and then it was left for 18 hours in contact with $\mathrm{H}_{2} \mathrm{SO}_{4}$ for further soaking (ASL-1d). In second and third case, the same process was repeated for 2 (ASL-2d) and 3 (ASL-3d) days respectively. A black product obtained in each case was washed with distilled water repeatedly until neutrality and dried in oven at $70{ }^{\circ} \mathrm{C}$ for 24 hours. The final products thus obtained were ground using mortar and pestle until a fine powder in each case.

\section{Preparation of various solutions}

Preparation of solutions of As(III): $1.32 \mathrm{~g}$ of accurately weighed arsenic trioxide $\left(\mathrm{As}_{2} \mathrm{O}_{3}, \mathrm{LR}\right.$ Grade, dried at 110 ${ }^{\circ} \mathrm{C}$ for an hour) was dissolved in $5 \mathrm{~mL}$ of $10 \mathrm{M}$ sodium hydroxide in a $1000 \mathrm{~mL}$ volumetric flask, shaken and then volume was made up to the mark with distilled water. Working solution of lower concentration ranging from 1 to $500 \mathrm{ppm}$ were prepared by appropriate serial dilution of stock solution with distilled water.

Standard buffer solutions: Buffer solutions of $\mathrm{pH} 4.0$, 7.0 and 9.2 were prepared by dissolving buffer tablets (Hi Media Laboratories Private Limited, India) of $\mathrm{pH}$ 4.0, 7.0 and 9.2 in $100 \mathrm{~mL}$ volumetric flasks with distilled water.

Sodium hydroxide and Hydrochloric solutions (0.1 M): About $2 \mathrm{~g} \mathrm{NaOH}$ and about $4.5 \mathrm{~mL}(11.14 \mathrm{M}) \mathrm{HCl}$ were dissolved separately in $500 \mathrm{~mL}$ volumetric flask and diluted up to the mark with distilled water.
Preparation of solutions of methylene blue (MB): 1.000 $\mathrm{g}$ of accurately weighed and dried methylene blue (Merck Life Science Private Limited, India) was dissolved in 1000 $\mathrm{mL}$ volumetric flask containing a little amount of distilled water and then volume was made up to mark with distilled water. Working solution of methylene blue was prepared by serial dilution of $1000 \mathrm{mg} \mathrm{L}^{-1}$ stock solution.

Ammonium molybdate reagent (I): About $12.5 \mathrm{~g}$ of accurately weighed ammonium heptamolybdate $\left[\left\{\left(\mathrm{NH}_{4}\right)_{6}\right.\right.$ $\mathrm{MO}_{7} \mathrm{O}_{24} .4 \mathrm{H}_{2} \mathrm{O}$ \}, L.R. Grade] was dissolved in $87.5 \mathrm{~mL}$ of distilled water. About $140 \mathrm{~mL}$ of concentrated sulfuric acid was added to $200 \mathrm{~mL}$ of distilled water cautiously. After cooling, the sulfuric acid solution was transferred to a $500 \mathrm{~mL}$ volumetric flask containing ammonium molybdate solution and the, volume was made up to the mark with distilled water.

Ammonium molybdate reagent (II): About $12.5 \mathrm{~g}$ of accurately weighed ammonium molybdate was dissolved in a $500 \mathrm{~mL}$ volumetric flask containing $250 \mathrm{~mL}$ of distilled water. To prepare exactly $5 \%$ of ammonium molybdate reagent (II) about $198 \mathrm{~mL}$ of ammonium molybdate regent (I) was added to the $500 \mathrm{~mL}$ volumetric flask containing ammonium molybdate reagent II, cooled and volume was made up to the mark with distilled water. Working solution of $0.5 \mathrm{M}$ ammonium molybdate was prepared by the dilution.

Potassium permanganate $(0.1 \mathrm{~N}, 250 \mathrm{~mL})$, sulfuric acid $(3 \mathrm{M}, 500 \mathrm{~mL})$ and Hydrazine hydrate $(0.5 \mathrm{M} 100 \mathrm{~mL})$ solutions were prepared separately.

\section{The $\lambda_{\max }$ and calibration curve for MB solution}

The solution having intermediate concentration $(5 \mathrm{mg} / \mathrm{L})$ was taken for the determination of $\lambda_{\max }$. The measurement was carried from 600 to $680 \mathrm{~nm}$ using spectrophotometer (2306, Electronics, India) by setting the blank solution at zero absorbance. The maximum absorbance was obtained at $665 \mathrm{~nm}$. After finding out the value of $\lambda_{\max }$, the wavelength was set at $665 \mathrm{~nm}$ and the absorbance of solution of different concentration (1 to $10 \mathrm{mg} / \mathrm{L}$ ) was measured. Thus obtained plot between absorbance and concentration of the solution is known as calibration curve for methylene blue solution. 


\section{The $\lambda_{\max }$ and calibration curve for As(III) solution}

During the preparation of calibration curve, the required volumes of diluted solutions were pipetted out and transferred in $25 \mathrm{~mL}$ volumetric flasks for the preparation of arsenic solutions of strength $0.1,0.2,0.3,0.4,0.5,0.6$, $0.8,0.9 \mathrm{mg} \mathrm{L}^{-1}$ and blank solutions. To each solution 4.5 $\mathrm{mL}$ of $0.5 \mathrm{~N}$ sulfuric acid and one drop of $0.1 \mathrm{~N}$ potassium permanganate were added and stirred for one minute. 3 $\mathrm{mL}$ of $0.5 \%$ ammonium molybdate and $3 \mathrm{~mL}$ of $0.5 \mathrm{M}$ hydrazine hydrate were added and then volume was made up to the mark with distilled water. The solution having intermediate concentration $(0.4 \mathrm{mg} / \mathrm{L})$ was taken for the determination of $\lambda_{\max }$. The measurement was carried from 810 to $870 \mathrm{~nm}$ using spectrophotometer by setting the blank solution at zero absorbance. The maximum absorbance was obtained at $840 \mathrm{~nm}$. After finding out the value of $\lambda_{\max }$, the wavelength was set at $840 \mathrm{~nm}$ and the absorbance of solution of different concentration was measured. Thus, the obtained absorption data was plotted to find the calibration curve.

\section{Characterization of Adsorbent Materials}

The phase detection was done using X-ray Diffractometer with monochromatic $\mathrm{Cu} \mathrm{K} \alpha$ radiation (D2 phaser Diffractometer, Bruker, Germany, at Nepal Academy of Science and Technology, NAST). Functional groups present in samples before and after adsorption of arsenic was analyzed by using Fourier transform infrared spectroscopy (IR Tracer 100, shimadzu, Japan at Central Department of Chemistry, Tribhuvan University). Activated carbon after modification with Conc. $\mathrm{H}_{2} \mathrm{SO}_{4}$ was analyzed using Electron diffraction spectroscopy (EDXGP, at Nepal Bureau of Standards and Metrology, Kathmandu) for the quantitative elemental analysis of adsorbent materials.

\section{Specific surface area determination of the ASLs}

The Langmuir adsorption isotherm model was used to determine the specific surface area of spinach leaves powder adsorbent material. For this $25 \mathrm{mg}$ of ASLs were added to the reagent bottle containing varying concentrations of methylene blue solutions from 10 to 300 $\mathrm{mg} \mathrm{L}^{-1}$. The solutions were agitated in a mechanical shaker for 24 hours. After 30 minutes, the supernatant solutions were pipetted out. The absorbances of resultant supernatant solutions were measured at $665 \mathrm{~nm}$ using spectrophotometer. The $\mathrm{Q}_{\max }$ value was calculated from Langmuir adsorption isotherm and this value was utilized for the determination of specific surface area in $\mathrm{m}^{2} \mathrm{~g}^{-1}$.

\section{Adsorption Studies}

Effect of pH: In order to study the effect of $\mathrm{pH}$ on arsenite adsorption, $50 \mathrm{~mL} 137.74 \mathrm{mg} / \mathrm{L}$ of arsenite solutions was poured in to a series of stoppered bottles and the $\mathrm{pH}$ of the solution was varied from 2 to 10 using the $\mathrm{pH}$ meter with the help of $0.1 \mathrm{M} \mathrm{NaOH}$ and $0.1 \mathrm{M} \mathrm{HCl}$. Flasks containing $50 \mathrm{mg}$ of ASL-2d in each were shaken for 24 hours in a mechanical shaker at $220 \mathrm{rpm}$.

Adsorption isotherm studies: The effect of arsenite concentration on the adsorption was studied under optimum pH. $50 \mathrm{mg}$ of ASL-2d was added to the $50 \mathrm{~mL}$ of arsenite solution having initial concentrations ranging from 7.91 to $228.62 \mathrm{mg} / \mathrm{L}$. The equilibration time for arsenite removal was less than 50 minutes. Each solution was agitated at $220 \mathrm{rpm}$ until the fulfillment of equilibration time.

Kinetics studies: The effect of Kinetics on the adsorption of iodine, chromium and arsenite removal was studied. Here, $50 \mathrm{mg}$ of ASL-2 was added to the $50 \mathrm{~mL}$ of arsenite solution having initial concentrations in the range of $200.39 \mathrm{mg} / \mathrm{L}$. Arsenite ion solution was agitated in a mechanical shaker at $220 \mathrm{rpm}$ for different time durations ranging from $5 \mathrm{~min}$. to 24 hours.

After shaking, each equilibrated solutions were filtered instantly using Whattmann No. 41 filter paper. Molybdenum blue method was used to determine the initial and equilibrium concentrations of arsenite ions.

\section{RESULTS AND DISCUSSION \\ Characterization of Adsorbent Materials X-ray diffraction (XRD) analysis}

The XRD pattern of raw spinach leaves and ASL-2d powders is shown in Figure 1. 


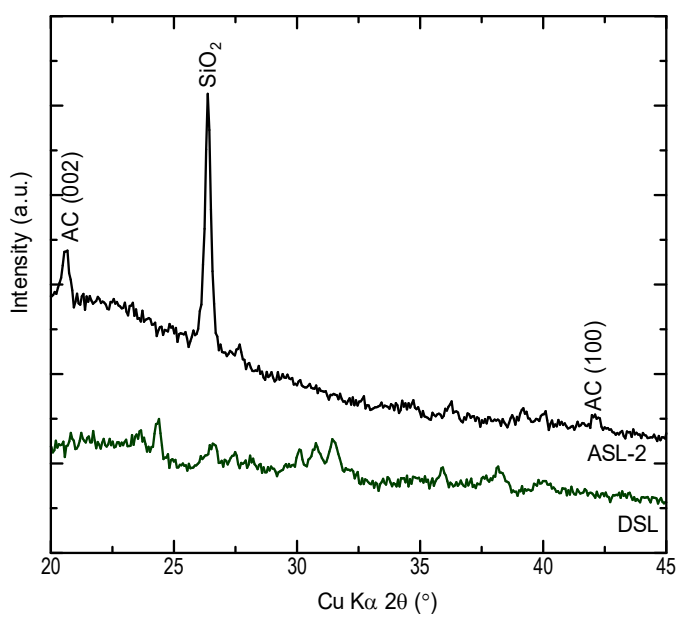

Figure 1: XRD patterns of raw sample (DSL) and spinach leaves powder adsorbent material (ASL-2).

Prepared sample was mostly amorphous showing weak and broad diffraction peaks of activated carbon at $2 \theta$ angles 20.5 and $42^{\circ}$ which is in trend with the previous report ${ }^{12}$. Sharp peak of $\mathrm{SiO}_{2}$ was obtained at $2 \theta$ angle $26.37^{\circ}$.

\section{FTIR analysis}

Raw spinach leaves, ASL-1d, ASL-2d and ASL-3d powders were analyzed using FTIR spectroscopy and is shown in Figure 2. The spectrum of raw spinach leaves powder (DSL) and spectra obtained from ASLs have a broad band between $3298 \mathrm{~cm}^{-1}$ representing the $\mathrm{O}-\mathrm{H}$ bonded. Aliphatic C-H stretching was obtained at 2914 and $2848 \mathrm{~cm}^{-1}$. The $\mathrm{C}=\mathrm{C}$ of arene was observed around $1600-1670 \mathrm{~cm}^{-1}$. The peak of C-O of ester, ether and phenol was observed below $1100 \mathrm{~cm}^{-1}$. Two peaks namely 1064 and $1016 \mathrm{~cm}^{-1}$ of dry spinach powder were merged during the treatment and one slightly broad but sharp peak appeared at $1030 \mathrm{~cm}^{-1}$.

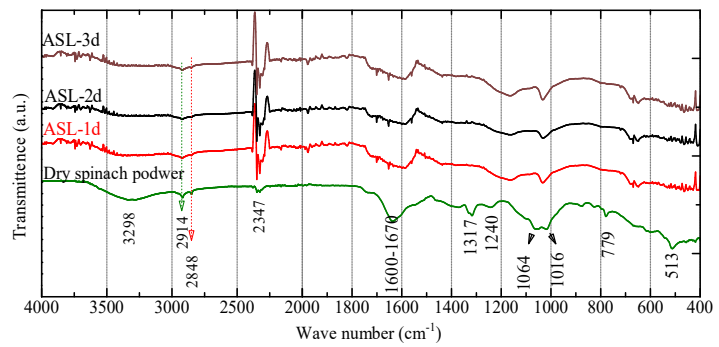

Figure 2: FTIR spectra of Dry spinach powder, ASL-1d, ASL-2d and ASL-3d samples.
The bonded O-H groups seem present in ASL which may also be responsible for adsorption as these may serve as $\mathrm{H}^{+}$ donor. Therefore, deprotonated bonded O-H groups may be involved in coordination with metallic and nonmetallic ions. The spectra analysis of ASLSs showed that there was clear band shift and decrease in intensity of the band at 3298,2914 and $1600 \mathrm{~cm}^{-1}$ in the sequence ASL-2d > ASL$3 \mathrm{~d}>$ ASL-1d. These are due to the result of high temperature in activation process that broke some more intermolecular bonds in ASL-2d in comparison with ASL1d. Less satisfactory parameters for ASL-3d in comparison with ASL-2d may be due to overdose of contact time of adsorbent with concentrated $\mathrm{H}_{2} \mathrm{SO}_{4}$. Hence, ASL-2d being the best adsorbent among 3 activated carbons, it was utilized for carrying out adsorption process for the adsorption of arsenic.

\section{EDX Analysis}

The EDX analysis confirmed the modification that the adsorbent material is composed of $94.5 \%$ carbon, $4.5 \%$ sulfur and remaining others (may be $\mathrm{SiO}_{2}$ ).

\section{Calibration curve for methylene blue solution}

The absorbance versus concentration plot for methylene blue solution is shown in Figure 3. It was found to be linear up to $10 \mathrm{ppm}$ and obeyed Beer-Lambert's law.

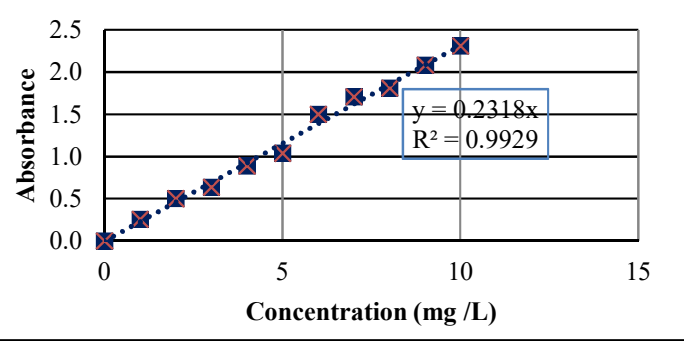

Figure 3: A plot of absorbance as a function of the concentration of methylene blue solution.

\section{Specific surface area determination}

For the determination of specific surface area, "Methylene blue adsorption method" was adopted widely for various natural solids such as activated carbon, charcoal, graphite, and silica etc ${ }^{13}$. This method is simple, rapid, easy, reliable and cheap. Therefore, this method can be performed in any laboratory easily. 
In this method, fixed amount of adsorbent is added to the different concentrations of methylene blue solution and the specific surface area is determined by using Langmuir adsorption isotherm.

By assuming monolayer adsorption of methylene blue on to the surface of sorbent particle, the specific surface area is calculated as:

$$
S_{M B}=\frac{Q_{\max } \cdot a_{M B} \cdot N}{M_{M B}} \quad \cdots \cdots \cdots
$$

Where, $\mathrm{S}_{\mathrm{MB}}$ is the specific surface area in $\mathrm{m}^{2} \mathrm{~g}^{-1}, \mathrm{Q}_{\max }$ is methylene blue adsorbed per gram of sorbent, $\mathrm{a}_{\mathrm{MB}}$ is the area occupied by one molecule of methylene blue in $\mathrm{m}^{2} /$ molecule, $\mathrm{N}$ is the Avogadro's number $\left(6.023 \times 10^{23}\right.$ molecules/mol) and $\mathrm{M}$ is the methylene blue molar mass i.e. $373.9 \mathrm{~g} / \mathrm{mol}^{13}$. Here, the $\mathrm{Q}_{\max }$ is equivalent to equilibrium adsorption capacity of the Langmuir equation. Linearized Langmuir curves for ASL-1d, ASL-2d and ASL-3d are shown in Figure 4.

From the slopes of these curves, the maximum adsorption capacities $\left(Q_{\max }\right)$ of methylene blue were determined which were used for the determination of specific surface area of the adsorbent materials with the use of Eqn. (1).

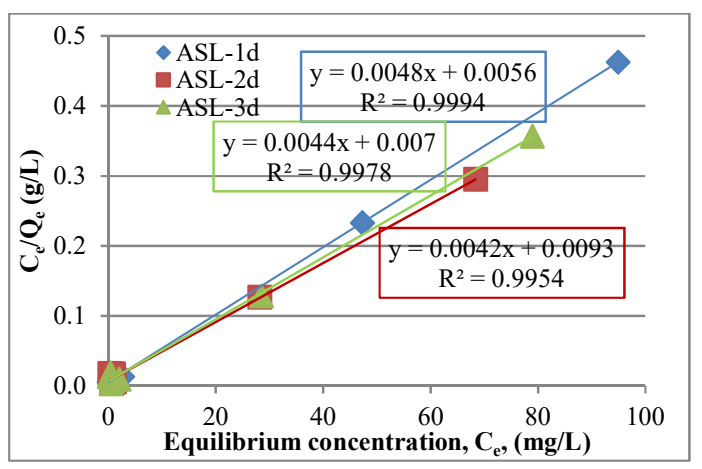

Figure 4: Plot of $C_{e} / Q_{e}$ versus $C_{e}$ of AsL-1d, ASL-2d and ASL-3d.

The specific surface area values are in the range of 436 , 499 and $476 \mathrm{~m}^{2} \mathrm{~g}^{-1}$ for ASL-1d, ASL-2d and ASL-3d respectively. The lowest specific surface area of ASL-1d in comparison with ASL-2d is expected to be due to the overdose of high temperature activation resulting in the formation of more ash content and other impurities that are capable of blocking the pores of the adsorbent.

\section{Effect of pH}

The results obtained for the adsorptive removal of arsenic as a function of $\mathrm{pH}$ is presented in Figure 5.

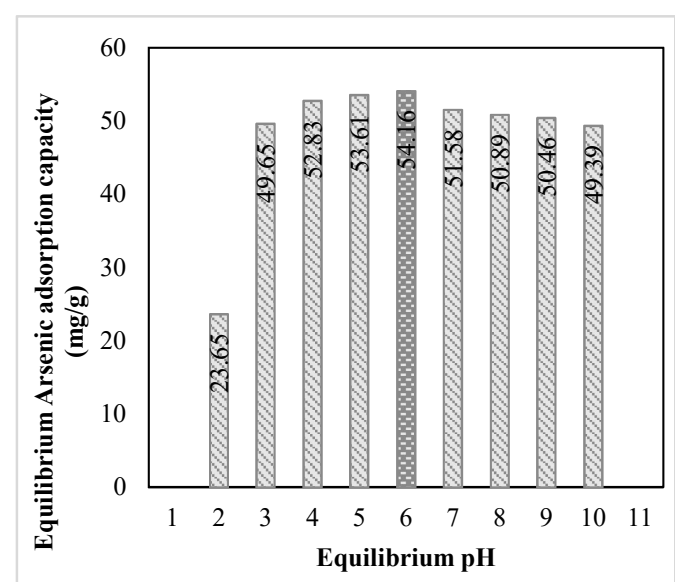

Figure 5: Effect of $\mathrm{pH}$ for the adsorption of Iodine on to the adsorbent ASL-2.

The adsorption yield of adsorbent was changed, when $\mathrm{pH}$ of solution containing As (III) ion was increased continuously.

The adsorption capacity was observed to be maximum at $\mathrm{pH} 6$ and minimum at $\mathrm{pH}$ 2. In general, at low $\mathrm{pH}$, concentration and mobility of $\mathrm{H}^{+}$ions are high. So they get preferentially adsorbed on the adsorbent rather than the other adsorbate molecules. Hence, adsorption of As (III) ions at very low $\mathrm{pH}$ was found to be minimum.

From literature survey, the maximum adsorption of arsenite on purely activated carbon was expected to occur at $\mathrm{pH} 9$ since, arsenite species exists as neutral $\mathrm{H}_{3} \mathrm{AsO}_{3}$ at $\mathrm{pH}$ range in between 1 to 9 and $\mathrm{AsO}_{2}{ }^{-}$at 9 and higher $\mathrm{pH}^{14}$. The experimentally obtained optimum $\mathrm{pH}$ value for arsenite adsorption was 6 . The fluctuation of the experimentally determined value from that of literature value may be either due to the involvement of partial ion exchange process arisen due to the presence of weakly acidic hydroxyl group, (as indicated by FTIR results) or adsorption of neutral $\mathrm{H}_{3} \mathrm{AsO}_{3}$ by physisorption. Due to the addition of $\mathrm{KMnO}_{4}$ in the solution just before the adsorption, some of the arsenite species are expected to be converted in to polar arsenate form which involved the ion exchange process in between the protonated hydroxyl group and As (V) ion. Some of the literatures data including fish scale, biomass, natural muscovite, goethite, biotite etc. have also shown the arsenite adsorption in 4 to $6 \mathrm{pH}$ range ${ }^{15,16}$. At $\mathrm{pH}$ value greater than 9, As (III) exist 
in anionic form and its adsorption on the negatively charged surface is unfavorable. Since, As(III) species is neutral in charge, thus the adsorption of this species on activated carbon is not chemisorption but a physical adsorption. Therefore, in this study, physisorption seemed to be playing a vital role during the adsorption process due to the presence of some arsenite species that are not oxidized. The optimum $\mathrm{pH}$ value for rest of the batch experiments were fixed at 6 for arsenic adsorption.

\section{Batch adsorption isotherm studies}

In 1918, Langmuir gave a relation between the amount adsorbed and the concentration for a unimolecular layer ${ }^{17}$. Langmuir assumed monolayer surface coverage of adsorbent molecules having energetically equivalent adsorption sites where, there was no any interaction in between the adsorbed molecules. The general form of equation representing the Langmuir's adsorption isotherm is given as:

$$
Q_{e}\left(=\frac{X}{M}\right)=\frac{b Q_{\max } C_{e}}{1+b C_{e}} \quad \ldots \ldots \ldots
$$

Where, $\mathrm{Q}_{\mathrm{e}}$ is equilibrium adsorption capacity $(\mathrm{mg} / \mathrm{g}), \mathrm{X}$ is the mass of adsorbate (mg), $\mathrm{M}$ is the mass of adsorbent (g), $\mathrm{Q}_{\max }$ is maximum adsorption capacity $(\mathrm{mg} / \mathrm{g}), \mathrm{b}$ is a constant related to adsorption energy $(\mathrm{L} / \mathrm{mg})$ and $\mathrm{C}_{\mathrm{e}}$ is the equilibrium concentration of the ions adsorbed $(\mathrm{mg} / \mathrm{L})$. Linearized form of equation (2) is:

$$
\frac{C_{e}}{Q_{e}}=\frac{1}{Q_{\max } b}+\frac{C_{e}}{Q_{\max }} \quad \ldots \ldots \ldots
$$

Thus, $C_{e} / Q_{e}$ values are plotted as a function of $\mathrm{C}_{\mathrm{e}}$ as to get a straight line with a slope equal to $1 / Q_{\max }$ and intercept equal to $1 /\left(Q_{\max } \cdot b\right)$. Here, slope and intercept are used for the determination of $\mathrm{Q}_{\max }$ and $\mathrm{b}$ respectively. The essential characteristics of the Langmuir isotherm can be explained in terms of a dimensionless separation factor $\left(\mathrm{K}_{\mathrm{L}}\right)$ which describes the type of isotherm, as defined by ${ }^{18}$.

$$
K_{L}=\frac{1}{1+b C_{i}}
$$

Where, $\mathrm{C}_{\mathrm{i}}$ is the initial concentration of the adsorbate in $\mathrm{mg} / \mathrm{L}$ and $\mathrm{K}_{\mathrm{L}}$ is the Langmuir equilibrium parameter. Shape of isotherm and nature of adsorption process is indicated by $\mathrm{K}_{\mathrm{L}},\left[\mathrm{K}_{\mathrm{L}}>1\right.$, unfavorable, $\mathrm{K}_{\mathrm{L}}=1$, linear, $0<\mathrm{K}_{\mathrm{L}}$
$<1$, favorable, $\mathrm{K}_{\mathrm{L}}=0$, irreversible]. Hence, for favorable isotherms, the $\mathrm{K}_{\mathrm{L}}$ value should lie between 0 and $1^{4,19}$.

The change in adsorption free energy $\Delta \mathrm{G}\left(\mathrm{kJ} \mathrm{mol}^{-1}\right)$ can be calculated by using Langmuir constant $\mathrm{b}$ as ${ }^{4}$ :

$$
\Delta G=-R T \ln (b)
$$

Where, $\mathrm{R}$ is the universal gas constant $\left(8.314 \mathrm{~J} \mathrm{~mol}^{-1} \mathrm{~K}^{-1}\right)$, $\mathrm{T}$ is temperature in kelvin and $\mathrm{b}$ is Langmuir constant in $\left(\mathrm{L} \mathrm{mol}^{-1}\right)$. The negative value of Gibb's free energy is an indicative of energetically favorable adsorption process. Its value lies in between -20 to $0 \mathrm{~kJ} \mathrm{~mol}^{-1}$ for physisorption process and in between -80 to $-400 \mathrm{~kJ} \mathrm{~mol}^{-1}$ for chemisorption process ${ }^{4,24}$.

\section{Freundlich adsorption isotherm}

Freundlich in 1909, proposed an empirical equation to represent the adsorption relationship and according to Freundlich, heterogeneous adsorbent surface containing non uniform distribution of heat of adsorption is suggested to adsorb more than one ion per binding site forming multilayer adsorption ${ }^{20}$. It is expressed as,

$$
Q_{e}=K_{F} C_{e}^{\frac{1}{n}} \quad \cdots \cdots \cdots
$$

Where, $\mathrm{K}_{\mathrm{F}}$ and $\mathrm{n}$ are Freundlich isotherm constants related to adsorption capacity and intensity of adsorption respectively. The value of $1 / \mathrm{n}$ lies generally in between 0 and 1. On taking logarithms on both sides of equation (7),

$$
\log Q_{e}=\log K_{F}+\frac{1}{n} \log C_{e} \quad \ldots \ldots \ldots
$$

Thus, $\mathrm{K}_{\mathrm{F}}$ and $\mathrm{n}$ can be determined, if the values of $\log \mathrm{Q}_{\mathrm{e}}$ are plotted as a function of $\log \mathrm{C}_{\mathrm{e}}$. The slopes and intercepts of the linearized Langmuir and Freundlich plots

\begin{tabular}{|c|c|c|c|c|c|}
\hline \multirow[t]{2}{*}{ Ion } & \multicolumn{5}{|c|}{ Langmuir model } \\
\hline & $\begin{array}{l}\mathrm{Q}_{\max } \\
(\mathrm{mg} / \mathrm{g})\end{array}$ & $\begin{array}{l}b \\
(\mathrm{~L} / \mathrm{mg})\end{array}$ & $\mathrm{R}^{2}$ & $\begin{array}{l}\Delta \mathrm{G} \\
(\mathrm{kJ} / \mathrm{mol})\end{array}$ & $\chi^{2}$ \\
\hline \multirow{4}{*}{ Arsenic } & 58.48 & 0.097 & 0.9951 & -22 & 2.36 \\
\hline & \multicolumn{5}{|c|}{ Freundlich Model } \\
\hline & \multicolumn{2}{|c|}{$\begin{array}{l}\mathrm{K}_{\mathrm{F}} \\
{\left[(\mathrm{mg} / \mathrm{g})(\mathrm{L} / \mathrm{mg})^{1 / \mathrm{n}}\right]}\end{array}$} & $\mathrm{n}$ & $\mathrm{R}^{2}$ & $\chi^{2}$ \\
\hline & \multicolumn{2}{|l|}{14.45} & 3.44 & 0.9209 & 30.07 \\
\hline
\end{tabular}
were used to calculate the Langmuir and Freundlich parameters for the adsorption of arsenic on the adsorbent ASL-2d and shown in Table 1.

Table 1. Parameters of Langmuir and Freundlich constants for arsenic adsorption. 
Arsenic ion adsorption as a function of the equilibrium concentration plot for As (III) is shown in Figure 6.

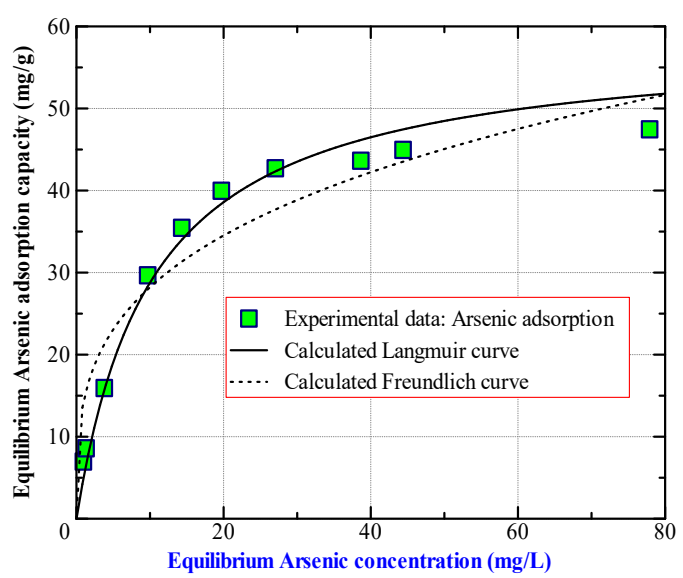

Figure 6: The adsorption isotherm of arsenic onto activated carbon obtained from spinach leaves.

Langmuir isotherm was better fitted by the experimental data in comparison with Freundlich isotherm, and hence the adsorption on the surface of ASL-2d was a monolayer adsorption with a high coefficient of determination $\left(\mathrm{R}^{2}\right)$. The $\mathrm{Q}_{\max }$ value for arsenic was $58.48 \mathrm{mg} / \mathrm{g}$. The $\mathrm{Q}_{\max }$ value of this adsorbent would have slightly more if there were no presence of $\mathrm{SiO}_{2}$ due to similar nature with arsenic.

The obtained $\mathrm{Q}_{\max }$ value was significantly higher than most of the other adsorbent materials such as $\mathrm{Zr}(\mathrm{IV})$ loaded saponified orange waste gel $(130 \mathrm{mg} / \mathrm{g})^{21}$, Fetreated biomass of Staphylococcus $(54.35 \mathrm{mg} / \mathrm{g})^{15}, \mathrm{Fe}(\mathrm{III})$ loaded pomegranate waste $(50 \mathrm{mg} / \mathrm{g})^{22}$, Lanthanum(III) and Cerium(III)-loaded orange waste gels $(43 \mathrm{mg} / \mathrm{g})^{10}$, $\mathrm{Fe} / \mathrm{Cu}$ nanoparticles $(19.68 \mathrm{mg} / \mathrm{g})^{19}$, quaternized rice husk $(18.98 \mathrm{mg} / \mathrm{g})^{23}$, rubber tyre derived activated carbon modified with alumina composite $(14.28 \mathrm{mg} / \mathrm{g})^{4}$ and tyre rubber-alumina composite $(13.51 \mathrm{mg} / \mathrm{g})^{4}$.

The negative value for free energy $\left(\Delta \mathrm{G}=-22 \mathrm{kJmol}^{-1}\right)$ confirmed the spontaneous, majorly physiosorption with few amount of chemisorption of As(III) on ASL-2d. The $\mathrm{K}_{\mathrm{L}}$ values (from Eqn. 4) are in between 0.04 and 0.57 indicating favorable adsorption.

\section{Error analysis for isotherm studies}

In order to evaluate the fit between experimental data and the various isotherm models, linear regression is the widely used approach where, closeness of the fit is determined from the value of the coefficient of determination $\left(\mathrm{R}^{2}\right)$. Linear regression analysis, however, transforms non-linear isotherm equations in to their linearized forms and this transformation violates the error variance and normality assumptions of standard least squares. In this sense, the non-linear chi-square analysis, $\chi^{2}$, shown in equation (8) can give more accurate results since this method compares all isotherms on the same abscissa and ordinate ${ }^{4}$.

$$
\chi^{2}=\sum \frac{\left(Q_{e, c a l}-Q_{e, e x p}\right)^{2}}{Q_{e, c a l}} \quad \cdots \cdots \cdots
$$

where, $Q_{e, c a l}$ is the equilibrium capacity obtained from expressions describing the different models $(\mathrm{mg} / \mathrm{g})$ and $Q_{e, \exp }$ is the equilibrium capacity $(\mathrm{mg} / \mathrm{g})$ obtained from the experimental data. Smaller $\chi^{2}$ values confirm a better correspondence between obtained data and isotherm model. In addition, nonlinear chi-square analysis can also be used in the case where, linear regression analysis leads to inadequate conclusions ${ }^{4}$.

The smaller value of $\chi^{2}$ for the Langmuir model than that of the Freundlich model mentioned in Table 1 also confirmed the Langmuir adsorption isotherm as best fitting model in each case.

\section{Batch Kinetic studies}

The pseudo-first order and pseudo second order kinetic models are used in this study. The adsorption capacity can also be used to describe adsorption mechanism of the metal ions on adsorbent surface where it is difficult to analyze using coefficient of determination values ${ }^{25}$.

\section{Pseudo-first order kinetic model}

Pseudo- first order kinetic model states that the rate of adsorption at any time $(\mathrm{dQ} / \mathrm{dt})$ is directly proportional to the amount of remaining unoccupied surface site (i.e. $\mathrm{Q}_{\mathrm{e}^{-}}$ $\left.Q_{t}\right)$. The differential form of pseudo- $1^{\text {st }}$ order rate equation (Lagergren, 1898) is expressed as ${ }^{25}$ :

$$
\frac{d Q}{d t}=K_{1}\left(Q_{e}-Q_{t}\right) \quad \cdots \cdots \cdots
$$

Where, $\mathrm{Q}_{\mathrm{e}}$ and $\mathrm{Q}_{\mathrm{t}}$ are the amounts of adsorbate adsorbed per unit weight $(\mathrm{mg} / \mathrm{g})$ of adsorbent at equilibrium and at time $(\mathrm{t})$, respectively and $\mathrm{K}_{1}\left(\mathrm{~min}^{-1}\right)$ is the first order adsorption rate constant. Linearized form of equation (8) 
for the boundary conditions $\mathrm{t}=0$ to $\mathrm{t}=\mathrm{t}$ and $\mathrm{Q}_{\mathrm{t}}=0$ to $\mathrm{Q}_{\mathrm{t}}=$ $\mathrm{Q}_{\mathrm{t}}$ is given as:

$$
\log \left(Q_{e}-Q_{t}\right)=\log Q_{e}-\frac{K_{1}}{2.303} \times t \quad \cdots \cdots \cdots
$$

Hence, $Q_{e}$ and $K_{1}$ can be calculated from slope and intercept of graph plotted between $\log \left(\mathrm{Q}_{\mathrm{e}}-\mathrm{Q}_{\mathrm{t}}\right)$ and time.

\section{Pseudo-second order kinetic model}

Pseudo-second order kinetic model states that the rate of adsorption at any time $(\mathrm{dq} / \mathrm{dt})$ is directly proportional to the square of amount of remaining unoccupied surface sites $\left\{\text { i.e. }\left(\mathrm{Q}_{\mathrm{e}}-\mathrm{Q}_{\mathrm{t}}\right)^{2}\right\}^{26}$. Therefore, the generalized form of kinetic rate law can be written as follows:

$$
\frac{d Q}{d t}=K_{2}\left(Q_{e}-Q_{t}\right)^{2} \quad \cdots \cdots \cdots
$$

Where, $\mathrm{K}_{2}\left(\mathrm{~g} \cdot \mathrm{mg}^{-1} \cdot \mathrm{min}^{-1}\right)$ is the pseudo second order adsorption rate constant. Linearized form of equation 11 is given as:

$$
\frac{t}{Q_{t}}=\frac{1}{K_{2} Q_{e}^{2}}+\frac{t}{Q_{e}} \quad \cdots \cdots \cdots
$$

Hence, $K_{2}$ and $Q_{e}$ values can be calculated from slope and intercept of graph plotted between $\left(\mathrm{t} / \mathrm{Q}_{\mathrm{t}}\right)$ and $\mathrm{t}$.

The kinetic parameters obtained from the slope and intercepts of pseudo first and pseudo second order rate equations for the adsorption of arsenic on ASL-2d are shown in Table 2:

Table 2: The order and rate constants for the adsorption of As on to ASL-2.

\begin{tabular}{|c|l|l|l|l|l|l|}
\hline Order & Slope & Intercept & $\mathrm{K}_{1}$ & $\mathrm{~K}_{2}$ & $\mathrm{Q}_{\mathrm{e}}$ & $\mathrm{R}$ \\
\hline $1^{\text {st }}$ & 0.011 & 1.160 & 0.0253 & & 3.19 & 0.8648 \\
\hline $2^{\text {nd }}$ & 0.019 & 0.019 & & 0.01830 & 53.8 & 0.9998 \\
\hline
\end{tabular}

The adsorption of arsenic on to ASL-2d follows pseudosecond order kinetics with the rate constant 0.01830 $\mathrm{g} /(\mathrm{mg} \cdot \min )$.

Kinetic curve representing the equilibrium adsorption capacity versus time is shown in Figure 7.

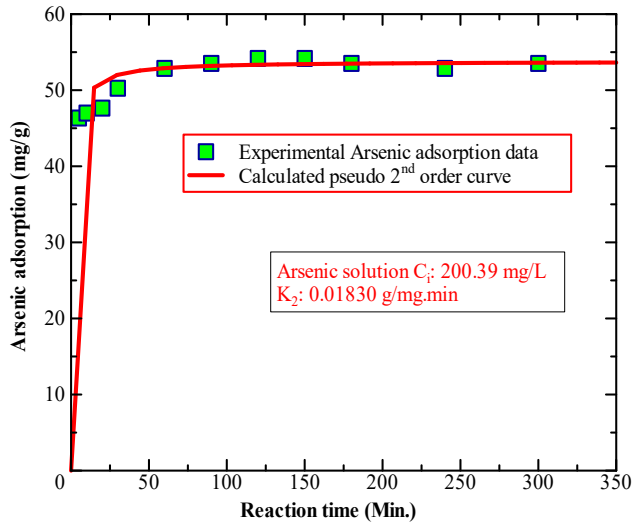

Figure 7: Kinetic plots for the adsorption of arsenic on ASL2d.

The amount of adsorption is sharply increased with increasing of contact time in the initial stage and then gradually increased to reach an equilibrium value in less than 60 minutes. A negligible effect on the amount of adsorption was observed on further increasing of contact time. The initial sharp increasing of adsorption capacity is due to the availability of more number of active sites at the initial stage. Number of active site decreases the equilibrium reaches after a certain interval of time.

\section{Mechanism of arsenic Adsorption}

The maximum adsorption at $\mathrm{pH} 6$ and the free energy of adsorption $(\Delta G)-22 \mathrm{kJmol}^{-1}$ indicates the complex pattern of adsorption mechanism involving more than one mechanism. Small amount of loosely bonded hydroxyl groups available for ion exchange process are responsible for chemisorption while, the pores available in activated carbon are responsible for majorly physisorption.

Intraparticle diffusion model proposed by Weber and Morris $^{27}$ identifies the process explaining rate determining step. The general form of equation is:

$$
Q_{t}=K_{i d} t^{0.5}+C
$$

Where, $K_{i d}\left(\mathrm{mg} / \mathrm{gh}^{0.5}\right)$ is the intraparticle diffusion rate constant. The $\mathrm{K}_{\mathrm{id}}$ and $\mathrm{C}$ can be calculated from the slope and intercept of graph plotted between $Q_{t}$ and $t^{0.5}$. The intercept of the plot describes boundary layer effect. The contribution of the surface adsorption in the ratecontrolling step increases if the intercept of the plot increases. This model is most satisfactorily explained if, $Q_{t}$ 
varies linearly with $\mathrm{t}^{0.5}$ by passing through the origin and if doesn't pass through the origin, it is not only the rate limiting step of the adsorption.

A plot of $\mathrm{Q}_{\mathrm{t}}$ and $\mathrm{t}^{0.5}$ is shown in Figure 8 .

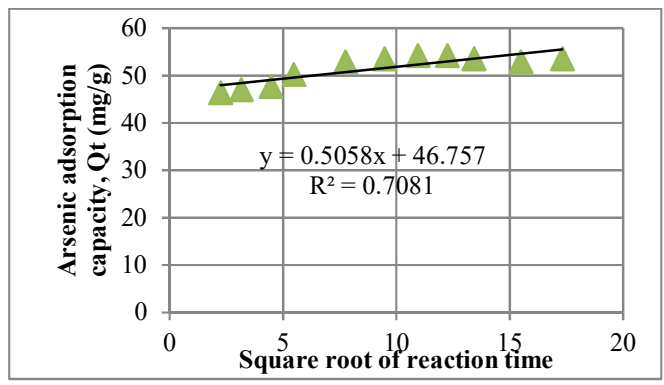

Figure 8: Plot of $Q_{t}$ versus $\sqrt{t}$ for the adsorption of arsenic on ASL-2d.

The $\mathrm{Q}_{\mathrm{t}}$ versus $\sqrt{t}$ plot does not pass through the origin showing that the intraparticle diffusion model was not the rate limiting step. The $\mathrm{K}_{\mathrm{id}}$ and $\mathrm{R}^{2}$ values obtained from the plot are 0.5058 and 0.7081 respectively.

The FTIR spectra of the adsorbent before and after the adsorption are shown in Figure 9. The diminishing of hydroxyl peak after adsorption may be due to the involvement of small amount of hydroxyl group in the adsorption process. Peaks of background $\mathrm{CO}_{2}$ seen at $2200-2400 \mathrm{~cm}^{-1}$ was vanished after arsenic ions adsorption showing that arsenic ions are preferentially adsorbed with expelling out physically adsorbed $\mathrm{CO}_{2}$. The broad peaks of ASL-2 at 1564-1640 and $1436 \mathrm{~cm}^{-1}$ were diminished due to the saturation of surface with the adsorption of arsenic.

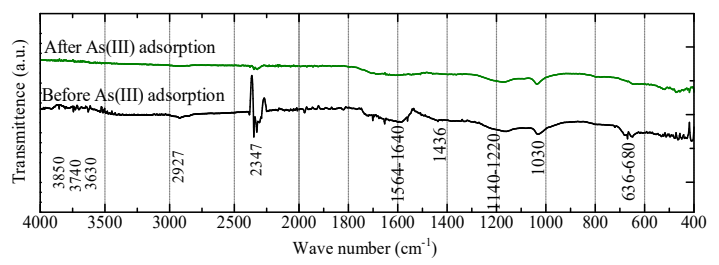

Figure 9: FTIR Spectra of before and after As (III) adsorption on the adsorbent obtained from Spinach leaves, ASL-2.

\section{CONCLUSION}

Low cost adsorbent materials were prepared from waste spinach leaves by chemical treatment with conc. $\mathrm{H}_{2} \mathrm{SO}_{4}$ and were characterized with various techniques. The adsorption of arsenic was found maximum at $\mathrm{pH}$. The equilibration time for adsorption was less than 60 minutes and the adsorption followed pseudo-second order kinetics with the rate constant of $0.01830 \mathrm{~g} /(\mathrm{mg} \cdot \mathrm{min})$. The equilibrium adsorption capacity was $58.48 \mathrm{mg} / \mathrm{g}$. The negative $\Delta \mathrm{G}$ value of $-22 \mathrm{~kJ} / \mathrm{mole}$ indicted that adsorption process was spontaneous, feasible and physiosorption with small amount of chemisorption type.

\section{REFERENCES}

1. Feng, N.et al. 2011. Biosorption of heavy metals from aqueous solutions by chemically modified orange peel. Journal of Hazardous Materials. 185: 49-54.

2. Fu, F., and Wang, Q. 2011. Removal of heavy metals ions from wastewaters: A review. Journal of Environmental Management. 92: 407-418.

3. Baby, J. et al. 2010. Toxic effect of heavy metals on aquatic environment. International Journal of Biological and Chemical Sciences. 4(4): 939-952.

4. Karmacharya, M. S. et al. 2016. Removal of As (III) and As(V) using rubber tyre derived activated carbon modified with alumina composite. Journal of Molecular Liquids. 216: 836-844.

5. Singh, T. S. and Pant, K. K. 2004. Equilibrium, Kinetics and thermodynamics studies for adsorption of As (III) on activated alumina. Separation and Purification Technology. 36(2): 139-147.

6. Kuriakose, S., Singh, T. S. and Pant, K. K. 2004. Adsorption of As (III) from aqueous solution on to iron oxide impregnated activated alumina. Water Quality Research Journal of Canada. 39(3): 258266.

7. Tchounwou, P. B. et al. 2012. Heavy metal toxicity and the environment. Experimentia Supplementum. 101: 133-164.

8. Thakur, J. K. et al. 2011. Arsenic contamination of ground water in Nepal-an overvie., Water. 3: 1-20.

9. Ratnaike, R. N. 2003. Acute and chronic arsenic toxicity. Postgraduate Medical Journal. 79(933): 391-396.

10. Biswas, B. K. et al. 2008. Effective removal of arsenic with lanthanum (III), cerium (III)-loaded orange waste gels. Separation Science and Technology. 43: 2144-2165.

11. Galla, N. R. et al. 2017. Nutritional, textural and sensory quality of biscuits supplemented with spinach (Spinacia oleracea L.). International Journal of Gastronomy and Food Science. 7: 20-26.

12. Xie, Z. et al. 2014. Production of Biologically Activated Carbon from Orange Peel and Landfill Leachate Subsequent Treatment Technology. Journal of Chemistry. 2014: 1- 9

13. Kaewprasit, C. et al. 1998. Application of methylene blue adsorption to cotton fiber specific surface area measurement: part I methodology. Journal of Cotton Science. 2: 164-173. 
14. Zhu, J. et al. 2015. $\mathrm{Fe}_{3} \mathrm{O}_{4}$ and $\mathrm{MnO}_{2}$ assembled on honeycomb briquette cinders $(\mathrm{HBC})$ for arsenic removal from aqueous solutions. Journal of Hazardous Materials. 286: 220-228.

15. Aryal, M., Ziagova, M. and Liakopoulou-Kyriakides, M. 2010. Study on arsenic biosorption using Fe(III)-treated biomass of staphylococcus Xylosus. The Chemical Engineering Journal. 162(1): 178-185.

16. Asta, M. P. et al. 2009. Arsenic removal by goethite and jarosite in acidic conditions and its environmental implications. Journal of Hazardous Materials. 171(1-3): 965-972.

17. Langmuir, I. J. 1918. The adsorption of gases on plane surfaces of glass, mica and platinum. Journal of the American Chemical Society. 40: 1361-1403.

18. Hall, K. R. et al. 1966. Pore- and solid-diffusion kinetics in fixedbed adsorption under constant-pattern conditions. Industrial \& Engineering Chemistry Fundamentals. 5(2): 212-223.

19. Babaee, Y., Mulligen, C. N. and Rahaman, M. S. 2017. Removal of arsenic (III) and arsenic (V) from aqueous solutions through adsorption by $\mathrm{Fe} / \mathrm{Cu}$ nanoparticle. Journal of Chemical Technology \& Biotechnology. 93(1): 63-71.

20. Freundlich, H. and Heller, W. 1939. The Adsorption of cis- and trans-Azobenzene. Journal of American Chemical Society. 61:2228-2230.

21. Biswas, B. K. et al. 2008. Adsorptive removal of As(V) and As(III) from water by a $\mathrm{Zr}(\mathrm{IV})$-loaded orange waste gel. Journal of Hazardous Materials. 154: 1066-1074.

22. Thapa, S. and Pokhrel, M. R. 2012. Removal of As(III) from aqueous solution using $\mathrm{Fe}(\mathrm{III})$ loaded pomegranate waste. Journal of Nepal Chemical Society. 30: 29-36.

23. Lee, C. K. et al. 1998. Removal of arsenic(V) from aqueous solution by quaternized rice husk. Environmental Technology. 20: 971-978.

24. Schiewer, S. and Balaria, A. 2009. Biosorption of $\mathrm{Pb}^{2+}$ by original and protonated citrus peels, equilibrium, kinetics and mechanism. Chemical Engineering Journal. 146: 211-219.

25. Lagergren, S. 1898. Zur theorie der sogenannten adsorption geloster stoffe. Kungliga svenska vetenskapsakademiens. Handlingar. 24: 139.

26. Ho, Y. S. and McKay, G. 1999. Pseudo-second order model for sorption processes. Process Biochemistry. 34(5): 451-465.

27. Karmacharya, M. S. 2017. Physicochemical characteristics of activated carbon obtained from waste tire and its alumina composite, PhD Thesis, Tribhuvan University, Kathmandu, Nepal. 